addition of a paramagnetic substance, resulting in a corresponding decrease in relaxation time. Data have been obtained for solutions containing $\mathrm{Fe}_{\Theta}{ }^{+++}$, $\mathrm{Cu}^{++}, \mathrm{Er}^{+++}$in concentrations from 0.0002 to 0.5 mol. The relaxation time is inversely proportional to the concentration and, roughly, to the square of the magnetic moment of the ion. For $\mathrm{F}^{\mathbf{1 9}}$ and $\mathrm{Li}^{7}$ resonances in liquids results have been found similar to those for protons. Furthermore, the deuteron resonance has been observed at $4.8 \mathrm{mc}$. in a water sample containing 50 per cent deuterium. The relaxation time for $D$ in this sample is 0.1 sec. Although the deuteron has a much smaller magnetic moment than the proton, this time is twenty times shorter than that for protons in the same sample, and must be ascribed almost entirely to the action of the quadrupole moment. One can repeat the above calculations for the electric quadrupole transitions by considering the 'local field spectrum' of the tensor grad E. With the known value of the quadrupole moment, one obtains the experimental value of the relaxation time for a reasonable value of $\operatorname{grad} \mathbf{E}$ in the polar liquid.

Finally, we must consider the spin-spin relaxation time and the closely related problem of the line width. In the limiting case of a solid in which the motion of molecules is very small, the line width can be calculated on the basis that the nuclei are at rest ${ }^{8}$, and spin-spin relaxation is produced by the fact that neighbouring nuclei precessing with the Larmor frequency can exchange their energy. On the other hand, in a liquid like water, this exchange will be much smaller, since the rapid Brownian motion smears out the spectrum and averages out the local field. We conclude that in liquids $\left(\tau_{c} \ll \mathrm{l} / \nu_{0}\right), T_{1}$ and $T_{2}$ are proportional and of the same order of magnitude. But while $T_{1}$ passes through a minimum at $\tau_{c}=$ $1 / 2 \pi v_{0}, T_{2}$ continues to decrease. The line width is a monotonic function of viscosity, at first linear, and asymptotically reaching a limiting value in the solid. Confirming this view, we find experimentally that the resonance line in water, glycerin, and other liquids at room temperature is extremely narrow. At $4.8 \mathrm{Mc}$./sec., an upper limit of 0.015 gauss has been established. The theoretical value according to the above considerations would be 0.007 gauss for glycerin and about $10^{-4}$ gauss for water. The broadening of the line in glycerin, mineral oil and ice, which can be observed at sufficiently low temperatures, is such that the line width is initially proportional to $\tau_{c}$. In glycerin at $-30^{\circ} \mathrm{C}$. the width is 1.5 gauss, in ice at $-5^{\circ} \mathrm{C} ., 5$ gauss, at $-30^{\circ} \mathrm{C}$., 15 gauss. The line width in solutions of ferric nitrate is proportional to the concentration of the paramagnetic ion, and is 0.6 gauss in a 0.5 mol. solution with a relaxation time $T_{1}=3 \times 10^{-4}$ sec.

A detailed account of this investigation will be sent to the Physical Review and will appear in a thesis to be submitted by one of us (N. B.) at the University of Leyden.

1 Purcell, E. M., Torrey, H. C., and Pound, R. V., Phys. Rev., 69, 37 $(1946)$.

${ }^{2}$ Heitler, W., and Teller, E., Proc. Roy. Soc., A, 155, 629 (1936).

' Rollin, B. V., Nature, 158, 669 (1946).

- Bloch, F., Hansen, W. W., and Packard, M., Phys. Rev., 70, 474 (1946).

- Bloembergen, N., Pound, R. V., and Purcell, E. M., Phys. Rev., 71, 466 (1947).

-Wang, Ming Chen, and Uhlenbeck, G. E., Rev. Mod. Phys., 17, 323 (1945).

"Debye, P., "Polar Molecules" (New York, 1945), chap. 5.

${ }^{8}$ Purcell, E. M., Bloembergen, N., and Pound, R. V., Phys. Rev., '70, 988 (1946).

\section{STATE LABORATORY FOR EXPERIMENTAL BIOLOGY AND MEDICINE, NOVI SAD, YUGOSLAVIA}

\author{
By Dr. PETAR N. MARTINOVITCH \\ Director
}

$\mathrm{W}$ HILE fighting was still going on in the Pannonian plains north-west of Beograd in 1944, a small group of young medical men and medical students (most of them in uniform) was busy collecting material left behind by the Germans, destined to become the nucleus of the present Laboratory for Experimental Biology and Medicine at Novi Sad, Yugoslavia. In due course they called on me to tell me that they wanted a laboratory for biomedical research. A site for the laboratory was yet to be found. Eventually, a deserted villa on the outskirts of the town was selected; but it was in an appalling condition, and many months of work were necessary to make it suitable for our purpose.

The United Nations Relief and Rehabilitation Administration sent a large amount of laboratory material to Yugoslavia; but it had to be shared by many laboratories and much of it was assigned to field work. Some valuable items, however, were allotted to our institute. Finally, due credit should be given to the progressive citizens of Novi Sad, who spared no effort to help the new laboratory. To-day the Laboratory is a State institution, and the authorities are giving ample credits for its support.

The available space in the Laboratory consists of four large rooms and six smaller ones. One room has been fitted for tissue culture work, and in the cellar there are a workshop, a washing room and a room where experimental animals can be kept. The building stands in a small park, and at the back is a garden with an enclosed space for poultry. The Laboratory is equipped with essential apparatus, instruments and a fair amount of glassware and necessary chemicals ; all the equipment of my tissue. culture laboratory at Beograd was transferred to Novi Sad. The Laboratory owns eight hectares of arable land, where the animals are kept and the animal food grown.

Although the official status of the Laboratory was established in May 1946, experimental work did not begin until several months later.

The new Laboratory is being organised on a modest scale along the lines of the Strangeways Research Laboratory at Cambridge. No separate departments are planned and no programme of 'division of labour' on the research level will be attempted. Each laboratory unit will be developed around the man and the field in which he is most interested. Collab. oration will be encouraged whenever necessary. No attempt will be made to encourage the Laboratory to grow beyond a certain definite size.

The Laboratory has four objectives, as follows : to bring under the same roof workers engaged in various fields of experimental biology and medical research; to establish the closest possible contacts with laboratories in other lands engaged in the same kind of work; to give an opportunity to promising young people interested in biomedical research to obtain elementary instruction in research methods, in order that they may be sent abroad sufficiently trained for advanced work; to 'popularize' bio. 
logical science by publishing books and articles on recent advances made in this field of research.

At present there are only two of us working in the Laboratory, a young doctor of medicine and myself. We are expecting a third, a bacteriologist, to come from the United States, where he has heen sent by the Rockefeller Foundation for special training. There are also several young men, now university students, whom the Laboratory hopes eventually to appoint to its staff. The problems at present being studied deal with the morphogenesis of the mammalian gonad, primarily of the germ cells, and with the gonadotrophic function of the pituitary gland.

The long years of war and occupation were a heavy blow to science in Yugoslavia. All research work was brought to a standstill. Completely shut off from the rest of the world, lacking even the most essential equipment for carrying on research, the small number of Yugoslav biologists, even if left alone by the enemy authorities (some were killed or imprisoned), were obliged to struggle for the bare necessities of life for themselves and their families. Since the War has ended, great efforts have been made to pick up the broken threads. But even now there are many obstacles. There is a shortage of almost every article essential to a research laboratory, great difficulties are encountered in replenishing depleted stocks, and reserve parts of precision apparatus are hard to get. Trained laboratory technicians are few, and so are electricians and mechanics acquainted with laboratory apparatus. We are also in dire need of technical books, journals and reprints of scientific papers. We would welcome reprints covering every field of biology and medicine, and the Laboratory at Novi Sad will be glad to forward them where they are most needed.

\section{THE CHEMICAL SOCIETY'S CENTENARY EXHIBITION}

$\mathrm{T}$ $\mathrm{HE}$ exhibition at the Science Museum, arranged as part of the centenary celebrations of the Chemical Society, was a memorable one. For the first time, through the co-operation of the director of the Museum, Dr. H. Shaw, a comprehensive display of exhibits illustrating the progress of chemistry in Britain over the past hundred years was housed under one roof.

The exhibition, organised on behalf of the Chemical Society and the XIth International Congress of Pure and Applied Chemistry, by a committee under the chairmanship of Sir Robert Robertson, was divided into two parts, illustrating the history and the everyday uses of chemistry. The historical side was arranged under ten headings each dealing with a section of the subject. Each section has been in the care of a panel of experts responsible for the selection of the exhibits, and for the corresponding chapter of the handbook to the exhibition. This handbook, "Chemical Progress" (London: H.M. Stationery Office. 1s. 6d. net), is a brief yet comprehensive survey of the British contribution to the science, which future students of chemistry may consult as a historical guide. The chairmen of the panels were Dr. A. E. Alexander, Dr. G. M. Bennett, Prof. J. D. Bernal, Prof. H. V. A. Briscoe, Dr. E. M. Crowther, Prof. C. W. Davies, Prof. D. H. Hey, Prof. C. N. Hinshelwood, Prof. E. K. Rideal, Prof. N. V. Sidgwick and Prof. M. W. Travers. The reports have been edited by Dr. F. Sherwood Taylor, curator of the Museum of the History of Science, Oxford.

A modern section dealing in a popular manner with "Chemistry in Everyday Life" was prepared by the Department of Scientific and Industrial Research, with the co-operation of the Agricultural Research Council, several research associations, and a number of industrial firms. The Central Office of Information prepared the layout of this part of the exhibition, which surveyed such fields as agriculture and food, health, homes and building, fuels, oil, transport and engineering. A popular account of this side was written by Dr. J. P. Lawrie, and this forms the second section of the handbook.

The exhibition was opened on July 14 by the president of the Chemical Society, Prof. C. N. Hinshelwood. The Minister of Education, Mr. George Tomlinson, was in the chair and welcomed the visitors. Prof. Hinshelwood in his opening speech said that the real adventures of science took place in the minds of men, and that much of the exhibition's interest would rely on the association of the objects to be seen with the men who used them.

It is impossible to do justice in the space of a short article to the many exhibits. In each branch of the subject the development was traced from the early pioneers. It was Faraday whose genius laid the foundations of so much of modern chemistry, His work on the alloys of steel was illustrated, as was that on the liquefaction of gases, the forerunner of all later researches in this field. His discovery of benzene was the start of modern organic chemistry, which was illustrated in all its aspects. His work on electrolysis has produced the modern science of electrochemistry, and the use of platinum as a catalyst. The visitor could also see, side by side with their more modern counterparts and developments, his samples of optical glass and colloidal gold.

Graham, too, the first president of the Chemical Society, was a pioneer whose experiments with simple apparatus led to the enunciation of the laws of diffusion in gases and liquids, and to the foundation of modern colloid science. The study of chemical reactions has increased our knowledge of molecular properties and brought about such material advances as photography and plastics. The early theories of valency and atomic structure put forward by New. lands and Crookes were demonstrated. These pointed the way for Mendeléeff, and also for Moseley, whose apparatus and ferrocyanide crystal were exhibited. In the range of inorganic chemistry the fundamental work of Dalton was illustrated by his diagrams of molecular structure. Near this were shown such diverse subjects as glass, precious metals, fluorine chemistry and fluorescent lighting, all items in which British chemists have played a decisive part.

The study of crystallography was represented by a large number of structural models and apparatus illustrating the development of theory and technique in this subject.

The important subject of agricultural chemistry, in which the early work of Lawes and Gilbert at Rothamsted pointed the way to modern scientific methods of increasing the fertility of the soil, was also given prominence.

It is, however, the organic chemist whose work offers the biggest variety of subjects. Each was illustrated by charts and specimens to show the structure, historical synthesis and applications of the substance. Individual exhibits showed early work in carbohydrates at St. Andrews and at Birmingham. 